\title{
Investasi Nilai Agama dan Membangun Perekonomian di Saat Pandemi COVID-19 dalam Mempersiapkan Sumber Daya Manusia yang Berkualitas
}

\author{
Yusutria $^{1}$, Yuzarion ${ }^{2}$, Ibdal $^{3}$, Nisa Amalia Kholifah ${ }^{4}$, Ikhsan Alfikri' ${ }^{5}$, Evinanda Ayu ${ }^{6}$ \\ Universitas Ahmad Dahlan, Ringroad Selatan, Kragilan, Tamanan, Kec. Banguntapan, Bantul, \\ Daerah Istimewa Yogyakarta 55191 \\ Email: yusutria@pai.uad.ac.id ${ }^{1}$
}

(Diajukan: 06 Juni 2021, Direvisi: 12 Juni 2021, Diterima: 14 Agustus 2021)

\begin{abstract}
ABSTRAK
Masalah; Pandemi COVID-19 telah melemahkan nilai-nilai yang diharapkan dari pendidikan dan ketahanan pangan serta berdampak pada psikologi masyarakat. Metode: Melakukan observasi awal, merumuskan strategi yang sesuai saat terjadi pandemi, melakukan diskusi dan tanya jawab dengan selalu memperhatikan tata cara kesehatan. Masa pandemi berdampak pada kualitas manusia pada pendidikan, ekonomi serta psikologis. Untuk itu diperlukan upaya membangun sumber daya manusia melalui bidang pendidikan dan ekonomi serta psikologi. Permasalahan yang terjadi karena rendahnya pemahaman masyarakat tentang meningkatkan pendidikan, ekonomi serta psikologis selama masa pandemi. Hasil: meningkatkan pemahaman cara kualitas SDM melalui pendidikan agama, ekonomi serta psikologi, melalui tanya jawab edukasi, diskusi cara membangun SDM melalui sektor pendidikan dan ekonomi serta psikologis. Kesimpulan: masyarakat memulai pendidikan agama dari rumah tangga masing-masing dengan memberikan contoh, kebiasaan, dan penghargaan. Dalam bidang ekonomi, masyarakat mengelola dan memanfaatkan sumber daya alam yang ada dan mendekatkan diri kepada Allah untuk memberikan kesehatan dan perlindungan.
\end{abstract}

Kata kunci: Sumber Daya Manusia, Nilai Keagamaan, Ekonomi, COVID-19

\begin{abstract}
Problem; The COVID-19 pandemic has weakened the values expected of education and food security and has had an impact on people's psychology. Methods: Conduct initial observations, formulate appropriate strategies during a pandemic, conduct discussions and ask questions by always paying attention to health procedures. The pandemic period has an impact on human quality in education, economy, and psychology. For this reason, efforts are needed to build human resources through the fields of education and economics as well as psychology. Problems that occur due to low public understanding about improving education, economics, and psychology during the pandemic. Results: increasing understanding of how to quality human resources through religious, economic, and psychological education, through educational questions and answers, discussions on how to build human resources through the education and economic and psychological sectors. Conclusion: people start religious education from their respective households by providing examples, habits, and rewards. In the economic field, the community manages and utilizes existing natural resources and draws closer to God to provide health and protection.
\end{abstract}

Keywords: Human Resources, Religious Values, Economy, COVID-19 


\section{PENDAHULUAN}

Masyarakat desa diidentikkan dengan masyarakat yang memiliki pendidikan rendah, pendapatan rendah, produktivitas rendah, pernikahan muda, terutama pada saat pandemi. Pandemi COVID-19 telah memberikan dampak yang luar biasa pada semua aspek kehidupan, terutama di bidang pendidikan, ekonomi, dan mentalitas. (Susanto, 2020), (Zuraida dkk., 2020), (Youn dkk., 2021). Mengatasi wabah tersebut, diharapkan masyarakat untuk menerapkan protokol Kesehatan yang ada, dan melakukan pekerjaan dari rumah. Masalah ekonomi juga sangat penting (Safriadi, Rahmatulah, 2021), (Abdimas, 2020), karena pembatasan pergerakan penduduk yang mengikutinya. (Tineu Indrianeu, 2021), (Yuliana dan Safina, 2021), (Purnomo dkk., 2021), (Shoss dkk., 2021). Sehingga dibutuhkan Kerjasama antara masyarakat dan pihak perguruan tinggi untuk mencoba memberikan solusi agar dapat keluar dari masalah yang ada. Hal tersebut bisa dilaksanakan melalui pengabdian kepada masyarakat (Qomariah, 2015). Sumber daya manusia yang memiliki potensi intelektual jika potensinya digali dan diterapkan dengan baik akan berdampak positif. Dampak positif yang diharapkan adalah adanya pembangunan berkelanjutan yang dapat meningkatkan daya saing bangsa itu sendiri (Wahyudi dan Hayati, 2020).

Kegiatan pelayanan masyarakat dilaksanakan oleh tim Dosen Universitas Ahmad Dahlan beserta mahasiswa. Pengabdian kepada masyarakat tersebut dilaksanakan di SD Muhammadiyah Munggang Wetan berstatus swasta, dengan Nomor Statistik Sekolah 102040411025. SD Muhammadiyah Munggang Wetan, dengan nomor NPSN; 20402876. Sekolah tersebut berada di desa Sidoharjo Samigaluh Kabupatern Kulonprogo Yogyakarta.

Kualitas pendidikan dan bagusnya ekonomi serta mentak yang baik, menjadikan suatu daerah akan baik, karena dengan ilmu manusia bisa memiliki yang diinginkan dengan mempertimbangkan unsur kemanusian yang ada (Walidin, 2016). Kegiatan layanan masyarakat bertujuan mencerdaskan masyarakat ke dalam proses pembangunan dimana masyarakat berinisiatif untuk memulai suatu proses kegiatan masyarakat guna memperbaiki situasi dan kondisinya sendiri. Pemberdayaan masyarakat hanya dapat terjadi jika masyarakat itu sendiri berpartisipasi (Susdarwono, 2019), (Amilia, Rokhani, dan Prasetya, 2020).

Pembentukan kehidupan ethical ditentukan oleh pembelaan terhadap ciri-ciri kepribadian, keluarga, budaya, dan kedudukan dalam struktur sosial yang membentuk kehidupan ethical, dengan demikian pendidikan karakter ethical yang perfect juga ditentukan oleh lingkungan yang mendukung (Badrianto dan Ekhsan, 2020), (Samtono, 
2011), dengan cinta membangun peradaban bangsa. Di balik keberhasilan ekonomi dan teknologi yang ditunjukkan oleh negara-negara maju, semua ini pada awalnya diilhami oleh nilai-nilai kemanusiaan agar kehidupan dapat dijalani dengan lebih mudah, lebih produktif, dan lebih bermakna (Jalaludin, 2012). Hal tersebut dalam upaya memajukan kesejahteraan masyarakat, pemberdayaan berarti mempersiapkan masyarakat dalam bentuk sumber daya (Rulitawati, Yanti dan Indrawari, 2019), kesempatan, pengetahuan, dan keterampilan untuk meningkatkan kapasitas masyarakat dalam menentukan masa depan, serta berpartisipasi dan mempengaruhi kehidupan (Sundarta, Angelina dan Akbar, 2020), (Syaekhu, 2021). Tujuan pengabdian ini dilaksanakan untuk meyiapkan sumber daya manusia yang unggul melalui investasi nilai agama dan membangun perekonomian pada pandemi.

\section{METODE}

Berdasarkan permasalahan yang dihadapi Mitra di masa pandemi COVID-19 telah melemahkan nilai-nilai pendidikan agama yang diharapkan dan ketahanan pangan serta berdampak pada psikologi masyarakat dirasa perlu untuk melaksanakan pembinaan dan pelatihan sesuai dengan kebutuhan mitra. Metode pelaksanaan kegiatan pengabdian, dengan metode partisipant active learning, dengan keikutsertaan setiap individu di dalam suatu kelompok tanpa membedakan usia, jenis kelamin, kelas social dan latar belakang Pendidikan yang tumbuh dari rasa kesadaran dan tanggungjawab. Adapun teknik pengumpulan data melalui pengamatan, angket dan dokumentasi.

Pola dalam mengatasi permasalahan tersebut, dalam menyelesaikan permasalahan yang dialami oleh orang tua dan guru SD Muhammadiyah Munggang Wetan dapat dirinci sebagai berikut:

1. Pendahuluan tentang: (1) Analisis kebutuhan (I), yaitu inventarisasi jenis-jenis kebutuhan yang diperlukan dalam melakukan diskusi dan tanya jawab; (2) Analisis kebutuhan (II), Mengumpulkan information peserta yang dapat mengikuti apa yang direncanakan; (3) Analisis kebutuhan (III) yaitu pengumpulan information materi pembelajaran yang dilakukan pada wali siswa dan guru SD Muhammadiyah Munggang Wetan; (4) Analisis kebutuhan (IV), adalah penentuan waktu dan tempat pelatihan serta penyusunan jadwal serta penentuan pemateri sesuai bidang keahliannya.

2. Tahap implementasi. Tahap pelaksanaan merupakan tahap dimana semua persiapan telah selesai dilakukan, kemudian pada tahap kegiatan pelatihan dapat dilaksanakan. Jenis pelatihan meliputi: 
a. Diskusi tentang membangun sumber daya manusia melalui penanaman nilainilai agama dimulai dari keluarga dalam menghadapi pandemi COVID-19.

b. Diskusi tentang membangun sumber daya manusia dengan memanfaatkan sumber daya alam yang ada dalam menghadapi pandemi COVID-19. C

c. Diskusi tentang membangun sumber daya manusia dengan membangun mentalitas yang kuat dalam menghadapi pandemi COVID-19.

Kegiatan ini dilaksanakan di tempat mitra yaitu SD Muhammadiyah Munggang Wetan Sidoharjo Samigaluh, Kabupaten Kulonprogo, Yogyakarta, pada Jumat 2 April 2021 hingga Jumat 23 April 2021 mulai pukul 08.30 hingga 15.00 WIB. Kegiatan ini dilakukan dengan memberikan penyuluhan kepada wali siswa dan master SD Muhammadiyah Munggang, dengan jumlah peserta 46 orang dan melibatkan 3 dosen dan 3 siswa.

\section{HASIL, PEMBAHASAN, DAN DAMPAK}

Pelayanan kegiatan tersebut dilaksanakan selama 6 bulan ini mengajarkan bagaimana mempersiapkan sumber daya manusia melalui penanaman nilai-nilai agama dan membangun perekonomian serta menanamkan mental yang kuat dalam menghadapi pandemi COVID-19, hal ini dilakukan sebagai upaya mempersiapkan sumber daya manusia yang lebih unggul untuk Indonesia maju, dengan tujuan memberikan pengetahuan kepada masyarakat khususnya orang tua, wali, dan ace tentang wawasan menanamkan nilai-nilai agama dan membangun perekonomian serta menanamkan mental yang kuat dalam menghadapi pandemi COVID-19 agar hari-harinya dapat diisi, dengan aktivitas positif berbagi dan memahami pentingnya menciptakan nilai-nilai agama, menyalurkan dan mengembangkan, dan memanfaatkan hasil sumber daya alam yang ada, serta membangun mentalitas yang kuat berdasarkan nilai-nilai agama.

Hal tersebut dapat dilihat pada dokumentasi kegiatan pengabdian kepada masyarakat pada gambar 1, 2, 3, 4. Pada gambar 1. Merupakan dokumentasi pada saat pemaparan materi tentang menyiapkan SDM unggul melalui pendidikan agama, pada gambar 2. adalah dokumentasi saat narasumber memberikan pemaparan materi tentang menyiapkan SDM yangberkualitas dengan memamfaatkan sumber daya alam yanga ada, Pada gambar 3. Dapat dilihat antusiasnya peserta dalam mengikuti sosialisasi tentang menyiapkan SDM unggul melalui investasi nilai agama, dan pada gambar 4. Merupakan dokumentasi saat berfose Bersama dengan peserta pengabdian kepada masyarakat setelah mengikuti kegiatan pengabdian. 


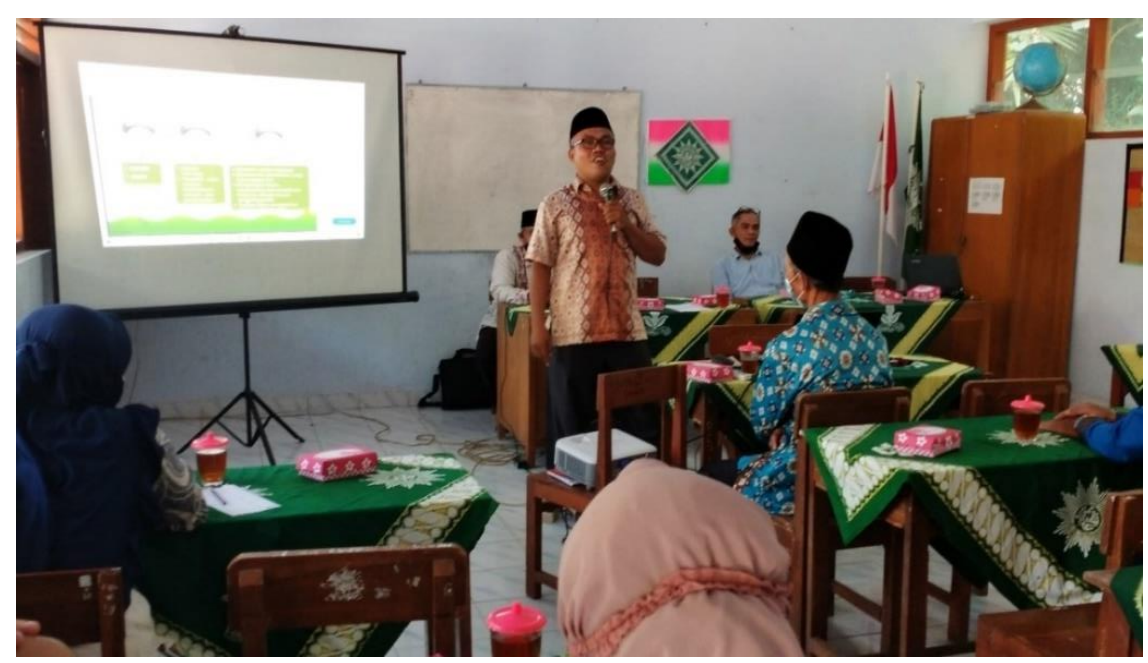

Gambar 1. Pemaparan materi tentang menyiapkan SDM unggul melalui pendidikan agama

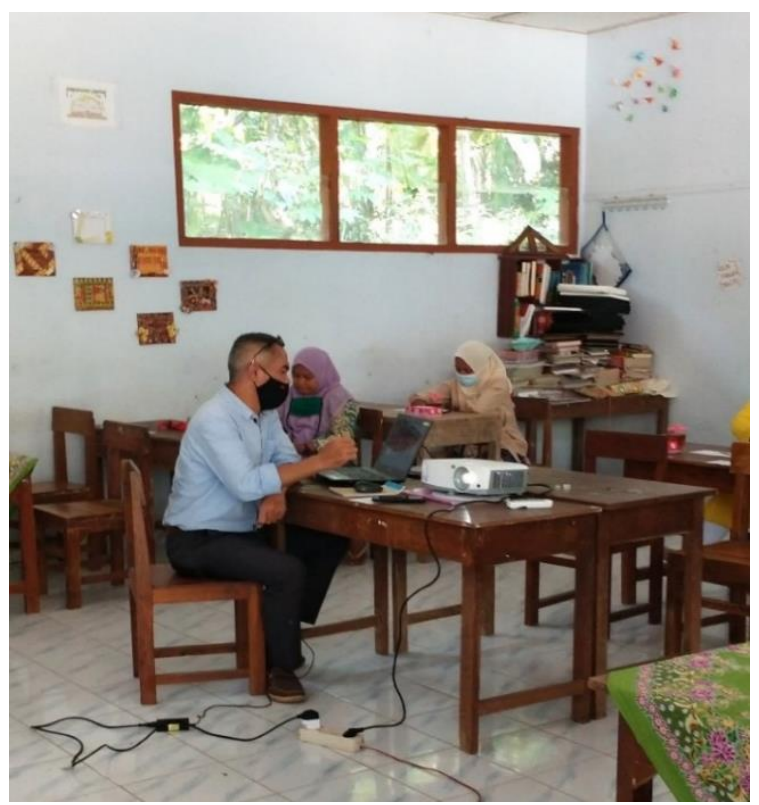

Gambar 2. Pemaparan materi tentang menyiapkan SDM yangberkualitas dengan memamfaatkan sumber daya alam yanga ada

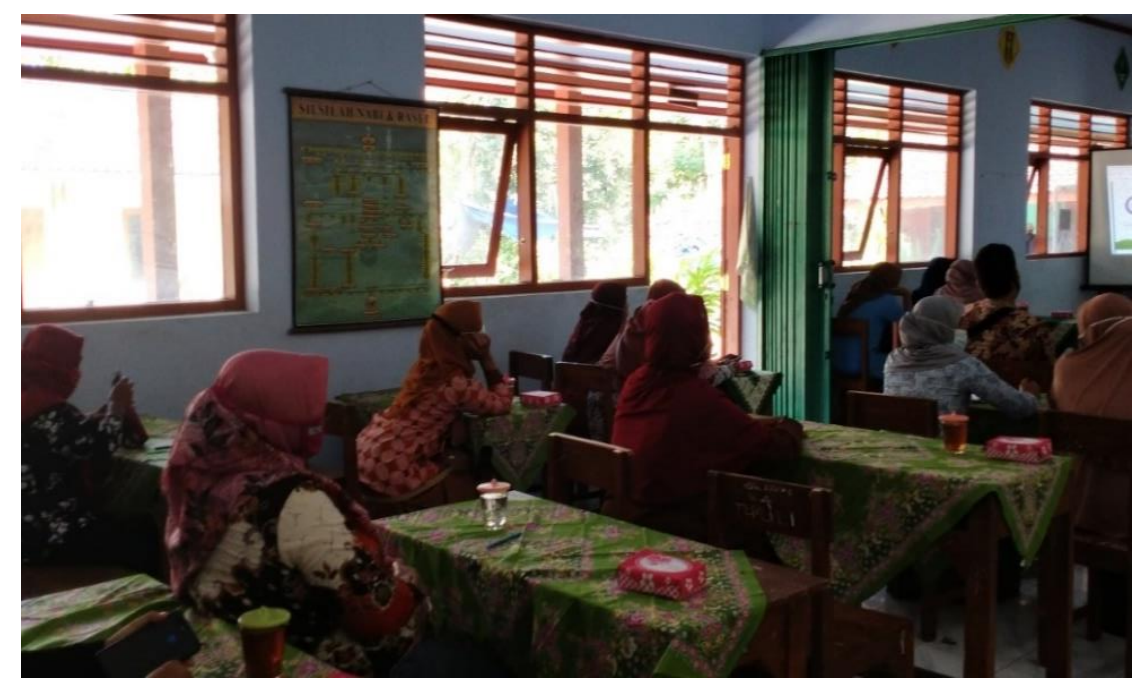

Gambar 3. Antusianya peserta dalam mengikuti sosialisasi tentang menyiapkan SDM unggul melalui investasi nilai agama 


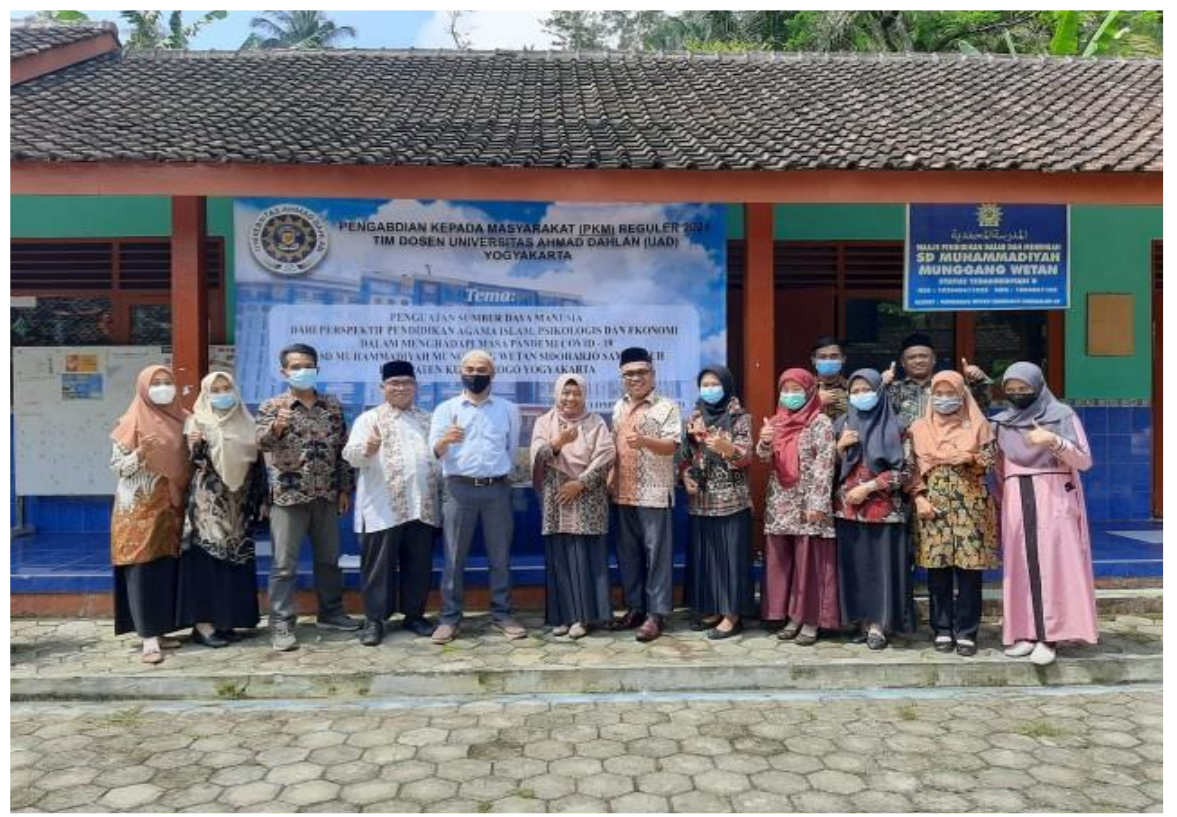

Gambar 4. Berfose Bersama dengan peserta pengabdian kepada masyarakat setelah mengikuti kegiatan pengabdian

Adapun hasil yang dicapai berdasarkan pengamatan selama kegiatan pengabdian masyarakat diperoleh beberapa hal positif, antara lain:

1. Orang tua, wali, dan guru di SD Muhammadiyah Munggang Wetan semakin sadar akan pentingnya penanaman nilai-nilai agama dalam keluarga guna membentuk sumber daya manusia yang berkualitas.

2. Pentingnya kerjasama yang baik antara orangtua wali dengan guru dalam penanaman nilai-nilai agama di lingkungan keluarga pada saat pandemi (Asmiatun dkk., 2021).

3. Peningkatan produktivitas wali dan guru di SD Muhammadiyah Munggang Wetan dalam memanfaatkan sumber daya alam untuk menunjang kebutuhan keluarga sehingga mampu memperkuat perekonomian di masa pandemi saat ini (Chasanah dkk., 2021).

Pendidikan yang baik dimulai dari keluarga dan diiringin dengan pengelolaan ekonomi yang baik serta selalu berdoa kepada Yang Maha Kuasa agar diberikan kemudahan. Hal tersebut tentunya harus direncanakan dengan matang dan bagus. Membentuk kecerdasan adalah kemampuan memberi makna ibadah bagi setiap perilaku dan aktivitas, melalui langkah dan pemikiran yang ada. Alamiah, terhadap manusia seutuhnya, dan memiliki pola pikir yang baik serta memiliki prinsip "semata-mata demi Allah". Pendapat lain mengemukakan bahwa kecerdasan dasar dari tindakan dan perilaku setiap orang berdasarkan iman yang dia miliki, dalam hal ini seseorang harus beriman kepada Allah karena segala macam tindakan didasarkan pada apa yang dia yakini. Kecerdasan, seorang 
individu akan selalu diawasi. Sang Pencipta yang berhati-hati dalam perbuatan dan perbuatannya juga adalah orang yang senantiasa menjaga diri dari perbuatan tercela yang dapat merugikan dirinya sendiri dan orang lain, tentunya dimulai dari keluarga. (Wellfarina Hamer, 2020).

Pentingnya pengelolaan sumber daya manusia dalam kehidupan sehari-hari menjadi tolak ukur perilaku dalam masyarakat. Kebiasaan dalam lingkungan keluarga juga dapat tercermin dalam interaksinya dengan sesama manusia di lingkungan sosialnya, (Khofiyah dan Cahyani, 2021). Oleh karena itu, kebiasaan baik dapat dikembangkan dalam lingkungan yang lebih luas dalam hal ini organisasi kemasyarakatan. Pendidikan keluarga yang merupakan pendidikan pertama bagi tumbuh kembang anak perlu dibiasakan mendidik anaknya agar dapat mengatur dirinya sendiri dengan baik, dan bagaimana diberi kesempatan untuk mandiri, disiplin, bertanggung jawab, dan berani mengambil resiko (Ahadin dan Yanuarianto, 2019) (Johansson dkk., 2021).

\section{SIMPULAN}

Dapat disimpulkan kegiatan pelayanan tersebut dapat dipahami tentang: Orang tua, wali, dan guru semakin sadar akan pentingnya penanaman nilai-nilai agama dalam keluarga guna membentuk sumber daya manusia yang berkualitas, Pentingnya kerjasama yang baik antara orangtua wali dengan guru dalam penanaman nilai-nilai agama di lingkungan keluarga pada saat pandemi, Peningkatan pengetahuan orantua wali dan guru dalam memanfaatkan sumber daya alam untuk menunjang kebutuhan keluarga sehingga mampu memperkuat perekonomian di masa pandemi saat ini

\section{UCAPAN TERIMAKASIH}

Tim pengabdian kepada masyarakat dari dosen Universitas Ahmad Dahlan tidak lupa menguucapkan terima kasih kepada;

1. Rektor Universitas Ahmad Dahlan (UAD) yang telah memberikan izin dan rekomendasi serta pembiayaan melalui LPPM (UAD)

2. Kepala sekolah berserta majlis guru SD Muhammadiyah Munggang Wetan Desa Sidoharjo Kulonprogo Utara, Kecamatan Samigaluh, Kabupaten Kulonprogo yang telah bersedia menjadi mitra. 
3. Seluruh orangtua wali murid SD Muhammadiyah Munggang Wetan Desa Sidoharjo Kulonprogo Utara, Kecamatan Samigaluh, Kabupaten Kulonprogo menghadiri kegiatan pengabdian pada masyarakat tersebut.

\section{DAFTAR PUSTAKA}

Abdimas, T. D. (2020). "Pengabdian Masyarakat Dengan UMKM Surabaya Berbasis Online Menggunakan Media Video Conference Google Meet ". Deepublish Publisher, Yogyakarta.

Ahmad Syaekhu, I. (2021). PKM Pemberdayaan Ekonomi Keluarga Kampung KB Nusa Indah Kota Makassar. MATAPPA : Jurnal Pengabdian Kepada Masyarakat, 4, 8-13.

Asmiatun, S., Winarti, T., Putri, A. N., Semarang, U., Hatta, J. S., Kulon, T., Pedurungan, K., Semarang, K., dan Tengah, J. (2021). Pelatihan Pemanfaatan Google Form sebagai Media Ujian Online di SD Negeri Pedurungan Kidul 02 Semarang melalui pemanfaatan teknologi informasi menggunkan perangkat mobile atau PC yang menggunakan aplikasi google form, google sites, google Lens, google . JPKMI (Jurnal Pengabdian Kepada Masyarakat Indonesia), 2(2), 93-101.

Badrianto, Y., dan Ekhsan, M. (2020). Strategi Pengembangan Sumber Daya Manusia Melalui Pemberdayaan dan Peningkatkan Kualitas Lingkungan Desa Cikedokan. KOMMAS: Jurnal Pengabdian Kepada Masyarakat Universitas Pamulang, 1(1), $168-175$.

Chasanah, U., Nursyifa, A., Juhaeri, J., dan Sofi'I, I. (2021). Pemberdayaan Masyarakat di Tengah Pandemi COVID-19 melalui Pembuatan Sabun Cuci dari Minyak Jelatah sebagai Upaya Mengurangi Pencemaran Lingkungan. JPKMI (Jurnal Pengabdian Kepada Masyarakat Indonesia), 2(1), 8-16. https://doi.org/10.36596/jpkmi.v2i1.111.

Jalaludin. (2012). Membangun SDM Bangsa Melalui Pendidikan Karakter. Jurnal Penelitian Pendidikan, 13(2), 1-14.

Johansson, T., Tishelman, C., Cohen, J., Eriksson, L. E., dan Goliath, I. (2021). Continuums of Change in a Competence-Building Initiative Addressing End-of-Life Communication in Swedish Elder Care. Qualitative Health Research, 104973232110129. https://doi.org/10.1177/10497323211012986.

Khofiyah, N., dan Cahyani, F. E. (2021). Pemberian Edukasi tentang Peran Orang Tua dalam Pencegahan COVID-19 pada Anak Pra Sekolah. JPKMI (Jurnal Pengabdian Kepada Masyarakat Indonesia), 2(2), 145-152. https://doi.org/10.36596/jpkmi.v2i2.152.

M Imam Sundarta, Putri Ria Angelina, Iyus Sidik Akbar, I. L. R. (2020). Mengembangkan Kualitas Sumber Daya Manusia Melalui Peningkatan Mutu Pendidikan, Keehatan dan Perekonomian Desa Barengkok. ABDI DOSEN, Jurnal Pengabdian Pada Masyarakat, 4(2), 181-190.

Purnomo, G. S., Andi, M., Dedy, S., Dewi, S., Mulya, S., dan Tujuan, A. (2021). Edukasi Obat dan Penanganan Kecemasan di Masa Pandemi COVID 19. MATAPPA : Jurnal Pengabdian Kepada Masyarakat, 4(1), 43-50. 
Qomariah, N. (2015). Pemberdayaan Masyarakat Desa Melalui Pengembangan "Soft Skill Pembuatan Kerupuk Samiler" Dalam Upaya Peningkatan Pendapatan Keluarga di Kabupaten Bondowoso. Jurnal Pengabdian Masyarakat IPTEKS, 1(2), 65-70.

Rulitawati, Sri Yanti, Karliana Indrawari, R. (2019). Sosialisasi Pendidikan Agama Islam pada Anak Usia Dini di Kelurahan Sukodadi Kecamatan Sukarami. Suluh Abdi: Jurnal Ilmiah Pengabdian Kepada Masyarakat, 1(2), 90-93.

Safriadi, Rahmatulah, A. (2021). Edukasi Masyarakat dalam Meningkatkan Ketahanan Pangan Keluarga di Masa Pandemi COVID 19. Jurnal SOLMA, 10(01), 165-172.

Samtono. (2011). Pembangunan Sumber Daya Manusia Di Sektor Pendidikan Dengan Segala Permasalahannya. Among Makarti, 4(7), 120-143.

Shoss, M. K., Horan, K. A., DiStaso, M., LeNoble, C. A., dan Naranjo, A. (2021). The Conflicting Impact of COVID-19's Health and Economic Crises on Helping. In Group and Organization Management (Vol. 46, Issue 1). https://doi.org/10.1177/1059601120968704.

Susanto, S. (2020). Efektifitas Small Group Discussion Dengan Model Problem Based Learning Dalam Pembelajaran Di Masa Pandemi COVID-19. Jurnal Pendidikan Modern, 6(1), 55-60. https://doi.org/10.37471/jpm.v6i1.125

Susdarwono, E. T. (2019). Pemberdayaan Masyarakat Desa Wanogara Wetan : Upaya Meningkatkan Peran Serta Warga Menuju Masyarakat Madani.

Tineu Indrianeu, D. (2021). Pemanfaatan Pekarangan Rumah Untuk Meningkatkan Ketahan Pangan pada Masa Pandemi Coivd-19. E-Amal Jurnal Pengabdian Kepada Masyarakat, 01(02), 231-240.

Udin Ahadin, Yanuarianto, D. (2019). Penyuluhan Pengembangan Manajemen Sumber Daya Manusia Karang Taruna Cidokom Gunung Sindur Bogor Jawa Barat. BAKTIMAS Jurnal Pengabdian Pada Masyarakat, 1(4), 205-211.

Wahyudi, D., dan Hayati, M. (2020). Pengabdian Masyarakat Dari Rumah Di Era New Normal. CV. Creative Tugu Pena, Lampung. https://www.academia.edu/download/64321984/PENGABDIAN MASYARAKAT DARI RUMAH DI ERA NEW NORMAL.pdf

Walidin, W. (2016). Arah Pengembangan Sumber Daya Manusia dalam Dimensi Pendidikan Islam. Jurnal Edukasi, 2(July), 147-163.

Wellfarina Hamer, Tubagus Ali Rachman Pujakesuma, Anita Lisdiana, Atik Purwasih, Karsiwan, W. (2020). Menyiapkan Sumber Daya Manusia Unggul Melalui Penanaman Nilai-Nilai Religius Pada Kegiatan Keagamaan di Desa Pulau Pehawang Kecamatan Marga Punduh. DEDIKASI: Jurnal Pengabdian Masyarakat, 2(1), 42-54.

Winda Amilia, Rokhani, Rendra C. Prasetya, B. S. (2020). Pembangunan Desa Wisata Gadingan Dan Kebutuhan Pengembangan Sumber Daya Manusia Dalam Pendekatan Community Based Tourism. JPPM; JURNAL PENGABDIAN DAN PEMBERDAYAAN MASYARAKAT, 4(1), 93-102.

Youn, S. Y., Lee, J. E., dan Ha-Brookshire, J. (2021). Fashion Consumers' Channel Switching Behavior During the COVID-19: Protection Motivation Theory in the 
Extended Planned Behavior Framework. Clothing and Textiles Research Journal, 39(2), 139-156. https://doi.org/10.1177/0887302X20986521.

Yuliana, Y., dan Safina, W. D. (2021). Pemberdayaan UMKM Pada Masa New Normal untuk Menopang Ekonomi Masyarakat. E-Amal Jurnal Pengabdian Kepada Masyarakat, 01(02), 57-62.

Zuraida.S.Ag., M., , Raihan Putri.St., M. E., , Maryana.S.Si., M. S., dan Zakaria, M. (2020). Penerapan Metode Pemberian Tugas dalam Pembelajaran PAI untuk Meningkatkan Prestasi Siswa Dimasa Pandemi Di MAS Al-Zahrah. PAI, Pemberian Tugas, Pembelajaran, Prestasi, 134-149. 